\title{
RSU Anatomy Museum: a historical collection with a contemporary approach
}

On 16 June 2021, the renovated RSU Anatomy Museum opened its doors to visitors. The museum exhibitions are based on the first anatomy training collection in Latvia. The collection was created in the Riga Anatomical Theatre in the 1920s and 1930s and used to train future medical specialists. Nowadays, the museum is open to everyone. Everyone is invited to look into what is usually seen only by anatomists or surgeons and to discover the diversity of human bodies. Skeletons, embryos, bones, body parts and organs - their structure and variations, healthy and afflicted with disease. Everything is real here. The museum is located at 9 Kronvalda Boulevard, in the Anatomical Theatre building complex.

\section{A brief overview of the history of the Museum}

The Anatomy Museum was founded in 1920 as a teaching museum of the Faculty of Medicine of the Higher School of Latvia (since 1923 the University of Latvia). The creation of the Anatomy Museum has been a collaboration of two scientists, the Swedish anatomist and anthropologist Gaston Backman (1883-1964) and the first Latvian anatomist and anthropologist Jēkabs Prīmanis (1892-1971). The collection was almost entirely created between 1920 and 1944. It reflects the scientific interests of anatomists and anthropologists of the first half of the 20th century, as well as the skills of anatomical preparators.

During the further existence of the Museum, the institutional affiliation and name of the Museum have changed several times. In 1950, the Faculty of Medicine of the University of Latvia was transformed 
into the Riga Medical Institute (today - Rīga Stradiņš University) and the Anatomy Museum became part of it as the Museum of the Department of Normal Anatomy.

In the early 1980s, at the Riga Medical Institute, like in many medical faculties around the world, the historical anatomical collection has experienced a gradually decreasing use in training medical students. Anatomists became less involved in the work of the Museum, but the role of medical historians from the Pauls Stradiņš Museum of Medical History located nearby was steadily gaining significance. Subsequently, in 1987 the Museum became an affiliate of the Pauls Stradiņš Museum for History of Medicine. In 1989, the affiliate was named after Jēkabs Prīmanis.

In 2000, the Museum's collection was included in the National Holdings of Museums. In 2017, by mutual agreement of Rīga Stradiņš University, the Pauls Stradiňš Museum of Medical History, the Ministry of Culture of the Republic of Latvia and the Ministry of Health of the Republic of Latvia, it was decided to include the collection of the Jēkabs Prīmanis Anatomy Museum in the Rīga Stradiņš University Museum. The decision to return the collection to its historical heir was made to ensure that this specific collection is preserved, researched and made available to the general public in accordance with modern museology principles.

With this agreement, the greatest possible changes took place in the history of the Museum's existence - the collection had to leave its original premises on the second floor of the Anatomical Theatre, in the former chapel hall, where it had been located since 1920. During almost a hundred years, the collection had grown together with its venue, the monumental, sacred spaces and historical glass cases, forming an inseparable whole. However, it was a collection that lost its original meaning but was unable to take on a new meaning nowadays. The aim of Rīga Stradiņš University was to revive the collection, give it a new voice and make it freely available to the public in a separate museum building.

Moving the collection to new premises raised the question - whether a $20^{\text {th }}$ century anatomical collection can make sense to a museum visitor of the $21^{\text {st }}$ century and how? 


\section{New content in a new exposition}

The new exposition of the RSU Anatomy Museum was created based on the belief that historical anatomical collections can be properly appreciated and respected only by acknowledging their existence, researching, using, exhibiting and discussing the identity of anatomical material, its place in our culture and its scientific applicability both historically and nowadays. Planning the new exposition, it was taken into account that the collection is inextricably linked with the time when it was created, so the Museum's exhibits tell more than just about anatomy. They tell the story of the people who created and preserved them. As well as about the history of anatomy and physical anthropology research in Latvia. Sometimes they tell about the people from whom the exhibits have been made. Therefore, within the exposition, modern elements interchange with historical ones, preserving the mood and layout characteristic of the anatomical collections of the first half of the $20^{\text {th }}$ century.

The exposition of the new museum is located right there in the territory of the Anatomical Theatre, in the former two-storey stable building, which after renovation has been adapted to the needs of a modern museum, adding both an underground floor and two outbuildings. The historical glass cases made specifically for the Museum in the 1920s have been preserved and restored, the thematic arrangement of the preparations in the historical exposition has been generally preserved as well. However, the historical preparations in the glass cases of the new exposition are complemented by various innovative multimedia solutions and digital exhibits, which make the exposition more vivid and easier for Museum visitors to perceive. The Museum app, which introduces 20 interesting objects of the Museum exposition, helps not to get lost in the large amount of preparations and information.

The permanent exhibitions of the Museum are located on two floors with an area of 300 square meters. On the first floor collections of normal anatomy and anthropology are located. The underground exposition houses more sensitive collections, such as the collection of congenital anomalies, embryology and teratology, as well as the collection of tattooed skin preparations. This arrangement allows museum visitors, such as children, not to view these more sensitive parts of the collection during their visit to the Museum. There are also storage rooms on the underground floor, where visitors can look through the glass walls, while on the second floor of the Museum there are rooms for the Museum's educational programmes, student seminars and other academic needs. 


\section{Museum transformation project team}

In total, the Museum transformation project lasted five years. During this time, the museum of a classical 20th century medical faculty was transformed into the Anatomy Museum, which ambitiously aims to be interesting not only for specialists in the field and medical students, but also for a much wider society. The curators of the new exposition are medical historian Ieva Lībiete and social anthropologist Ilze Sirmā. The exhibition design project and its realisation were carried out by DD Studio, an experienced company in the field of museums, under the guidance of Jānis Mitrēvics, the creative director. The content of the interactive and digital solutions of the exposition was created in cooperation with the medical education startup Anatomy Next. The brand of the museum was created by Kolektīvs LLC. The author of the building reconstruction design is the architect Arvīds Lìkops, the construction project was developed by Delta Construction LLC and the architect's office Nams. Reconstruction and adaptation of the building to the needs of the museum was performed by Velve LLC. The museum is located on Kronvalda Boulevard 9, in the Anatomical Theatre building complex, which originally was built for the Riga Orthodox Theological Seminar in 1877-1879 according to the project of the architect Heinrich Scheel.

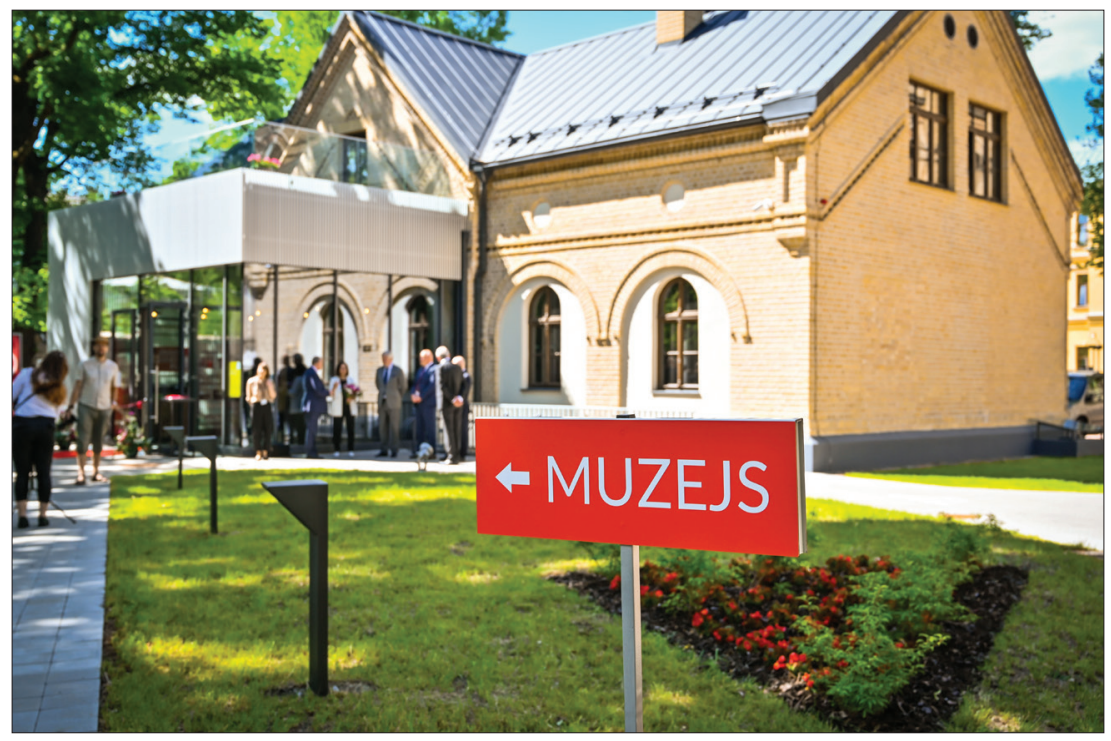

RSU Anatomy Museum on June 16, 2021. Photo: RSU 


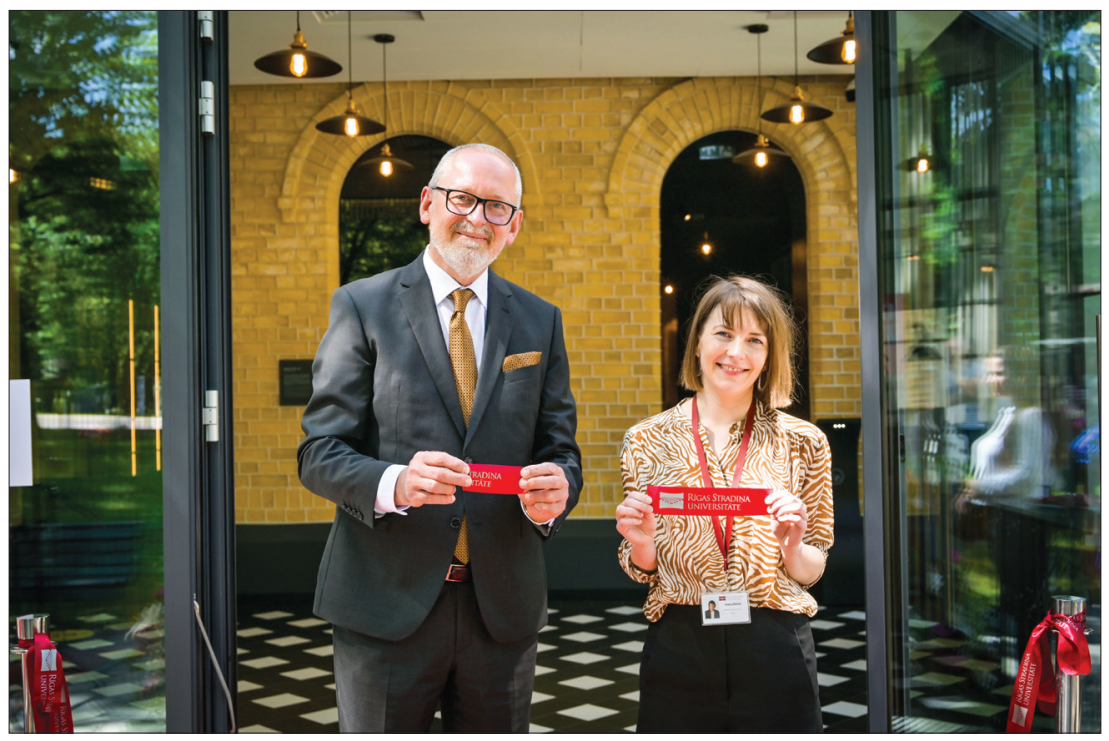

Museum curator assist. prof. Ieva Lībiete and RSU rector prof. Aigars Pētersons at the ribbon-cutting ceremony. Photo: RSU

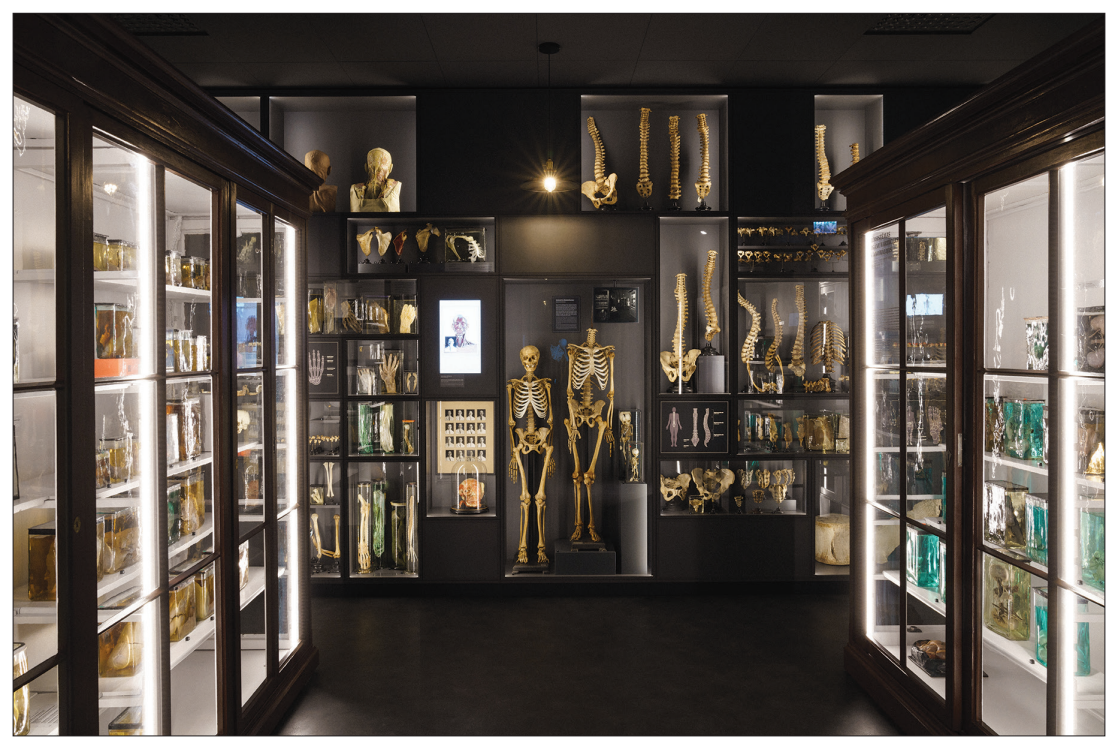

Anatomical collection. Permanent exhibition. Photo: Dd Studio 


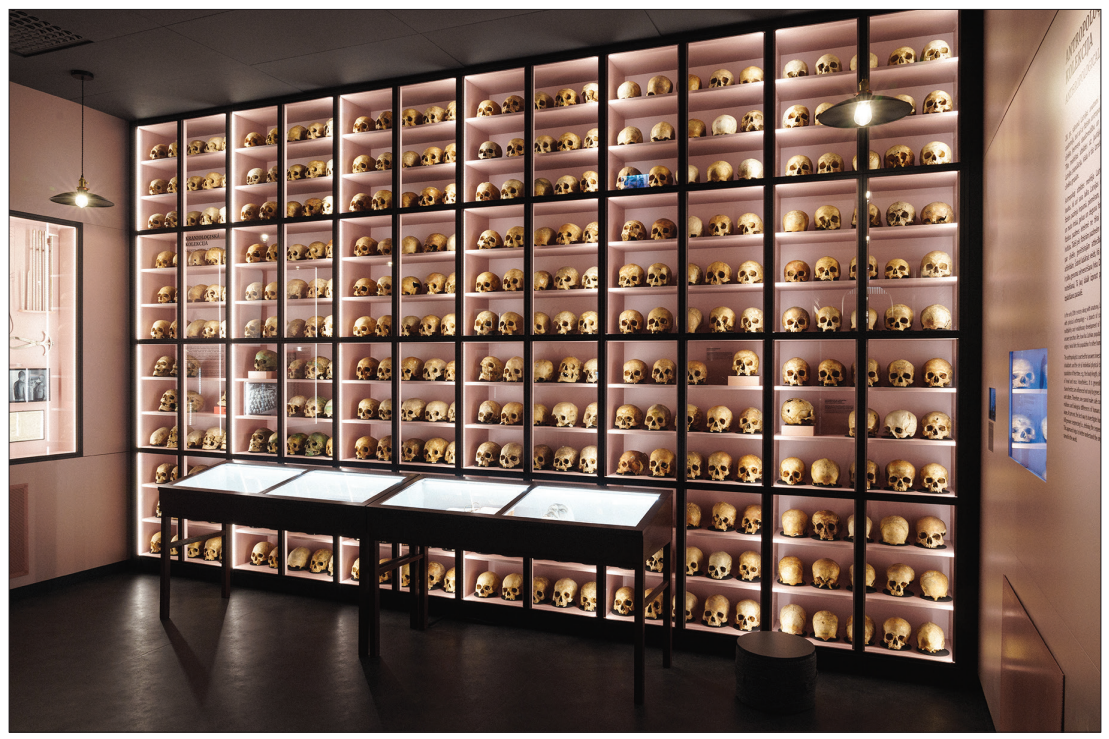

Anthropological collection. Permanent exhibition. Photo: Dd Studio

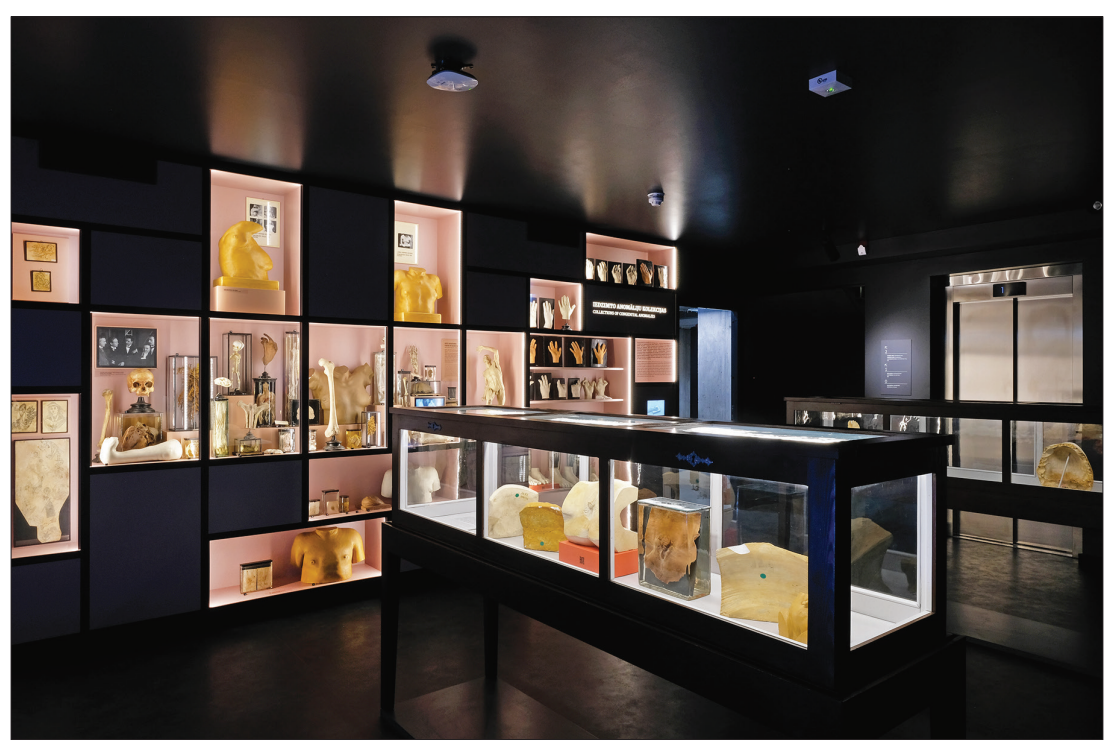

Congenital malformations. Permanent exhibition. Photo: Tone Studio 


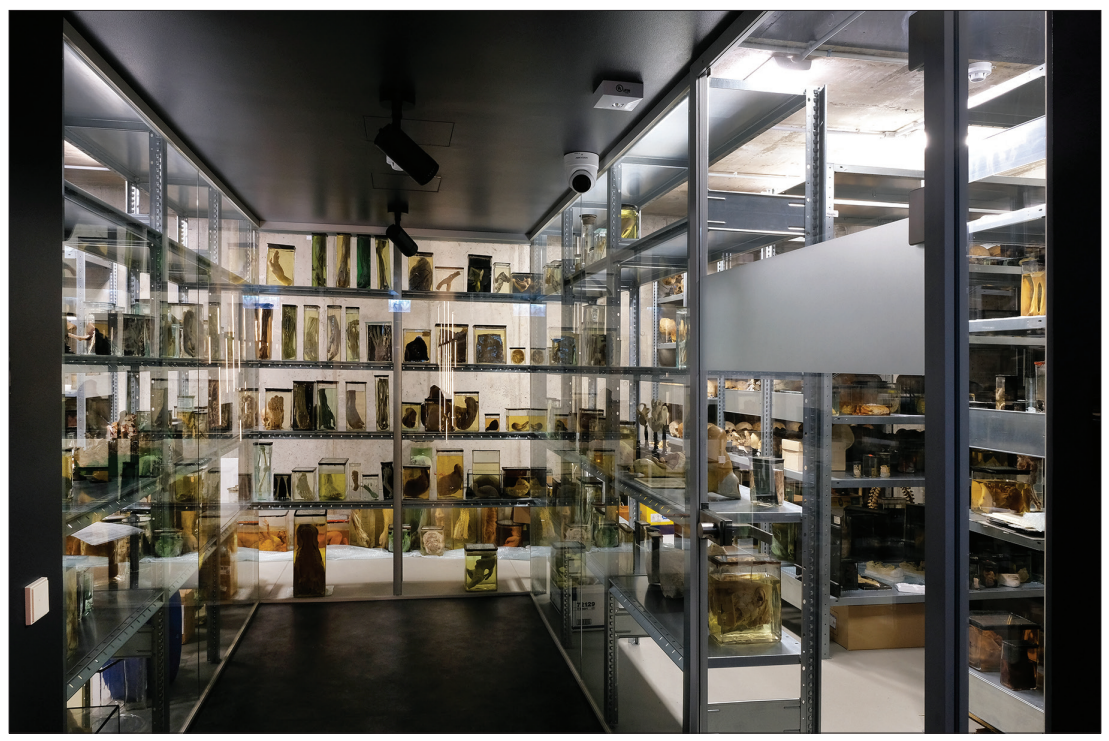

Storage rooms. Photo: Tone Studio

\section{Ieva Lībiete}

Dr. med., Rīgas Stradiṇa universitātes

Medicīnas vēstures institūts / Dr. med., Institute of the History of Medicine at Rīga Stradiñ̌ University 